\title{
The moderation effect of social factors on marketing factors in consumer research
}

\author{
Xiaochuang Wu \\ Central South University, Changsha \\ Helen Chen \\ Technological University Dublin, helen.chen@tudublin.ie \\ Xiaohong $\mathrm{Li}$ \\ Central South University, Changsha
}

Follow this and additional works at: https://arrow.tudublin.ie/buschmarart

Part of the Business Administration, Management, and Operations Commons, and the Marketing Commons

\section{Recommended Citation}

Xiaochuang Wu, Helen X. Chen \& Xiaohong Li (2019) The moderation effect of social factors on marketing factors in consumer research, Transnational Corporations Review, 11:2, 157-165, DOI: 10.1080/ 19186444.2019.1603778

This Article is brought to you for free and open access by the School of Marketing at ARROW@TU Dublin. It has been accepted for inclusion in Articles by an authorized administrator of ARROW@TU Dublin. For more information, please contact arrow.admin@tudublin.ie, aisling.coyne@tudublin.ie,gerard.connolly@tudublin.ie.

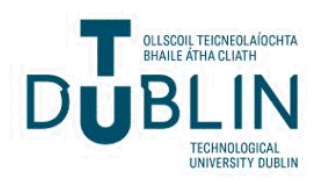




\section{The moderation effect of social factors on marketing factors in consumer research}

\section{Xiaochuang Wu, Helen X. Chen \& Xiaohong Li}

To cite this article: Xiaochuang Wu, Helen X. Chen \& Xiaohong Li (2019) The moderation effect of social factors on marketing factors in consumer research, Transnational Corporations Review, 11:2, 157-165, DOI: 10.1080/19186444.2019.1603778

To link to this article: https://doi.org/10.1080/19186444.2019.1603778

\section{Published online: 16 May 2019.}

Submit your article to this journal

Џ Article views: 398

Q View related articles $\asymp$

View Crossmark data $₫$

Citing articles: 4 View citing articles ๘ 


\title{
The moderation effect of social factors on marketing factors in consumer research
}

\author{
Xiaochuang $\mathrm{Wu}^{\mathrm{a}}$, Helen X. Chen ${ }^{\mathrm{b}}$ and Xiaohong $\mathrm{Li}^{\mathrm{c}}$

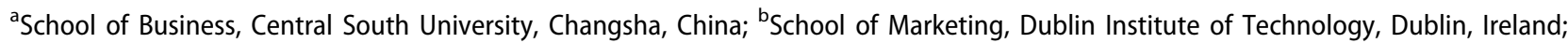 \\ 'School of Foreign Languages, Central South University, Changsha, China
}

\begin{abstract}
Consumer research tends to isolate the impact of marketing and social factors. Little has been done to include both. This paper aimed to find out what would happen when these two sets of factors are included. Two models were built in this paper, Model I with the marketing factors only and Model II with both the marketing and social factors. Data was collected in Ireland among more than 1473 transition year students in a personal survey regarding their willingness to learn Chinese. Data were analysed by using structural equation modelling (SEM). Results showed the two social variables, acculturation and intergenerational influence, significantly consolidated the effects of brand awareness on both brand trust and purchase behaviour; and they diminished the impact of brand trust on purchase behaviour. Empirical evidence suggested the worthiness for marketing researchers to examine both marketing and social factors in consumer research.
\end{abstract}

\section{ARTICLE HISTORY}

Received 25 January 2019 Revised 20 February 2019 Accepted 31 March 2019

\section{KEYWORDS}

Consumer research; marketing factors; social factors; structural equation modelling; Andrew Hayes' macro

\section{Introduction}

There seem to be at least two streams of consumer research. The first group of research tends to examine the impact of marketing factors on consumers, such as Keller (1983), Morgan and Hunt (1994), Chaudhuri and Holbrook (2001), Grant et al. (2008). For example, Chaudhuri and Holbrook (2001) argue that purchase behaviour is affected by some marketing factors such as brand loyalty, which in turn is determined by the brand trust. According to Morgan and Hunt (1994), consumer purchase behaviour is confirmed to be a relational asset of market implications for the development and maintenance of brand trust, which is affected by brand awareness. The second group of researchers, however, focus on the influence of social factors such as Durvasula and Lysonski (2015), Kang (2006). They argue that consumer is surrounded by global brands and global consumer cultures (Cleveland \& Laroche, 2007; Durvasula \& Lysonski, 2015) and thus social factors such as how much consumers are ready to accept foreign consumer culture, i.e. acculturation be of interest and importance. In this stream, it has been stressed in Heckler, Childers, and Arunachalam (1989) and Moore, Wilkie, and Lutz (2002) that parents influence their children on purchase behaviour through passing on information, attitudes, beliefs, resources and behaviours to their children; and children also influence their parents (De Mol \& Buysse, 2008). To date, little research has been done on the impact of both social and marketing factors on purchase behaviour. To fill in the gap, the focus of this paper is to combine these two sets of factors to examine consumer behaviour, specifically, on how social factors such as acculturation and intergenerational influence moderate the effects of those marketing factors such as brand awareness and brand trust on purchase behaviour.

\section{Literature review}

Purchase behaviour is always on the agenda of organisations and researchers in consumer research as it helps in understanding the customer acquisition rate, as well as the performance and competitiveness of organisations. There are a few different schools of thought on purchase behaviour. Ajzen (1991), in his classic work 'Theory of Planned Behaviour', proposes that purchase behaviour is an action which is a consequence of attitudes, norms and behavioural control. Similarly, Assael (2004) defines purchase behaviour as a tendency of acting, such as the 


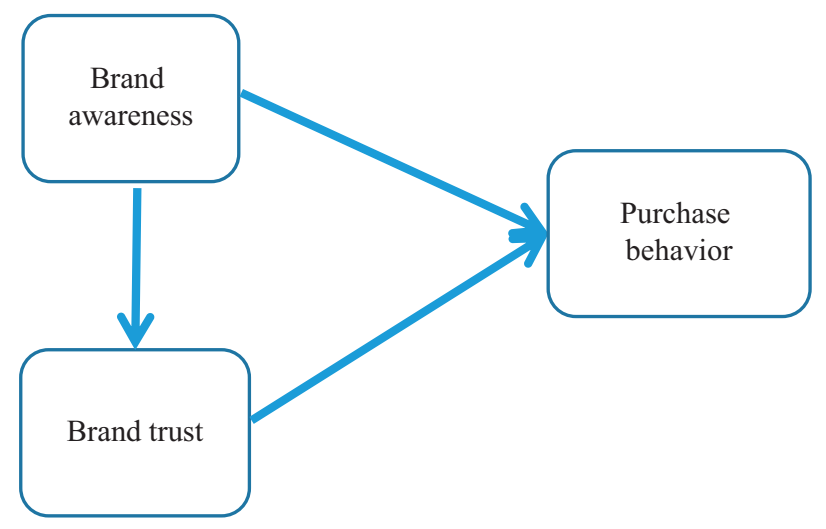

Figure 1. Relationships between Brand Awareness, Brand Trust and Purchase Behaviour.

actual purchase of a product or service. While acknowledging that some attributes need to be considered before consumers make a purchase decision, Schiffman and Kanuk (2010), however, treat purchase behaviour as a process that takes place prior to the purchasing decision. The procedural view of purchase behaviour is out of scope of the present paper. Instead, this present paper will follow Assael (2004)'s views of treating purchase behaviour as a tendency of purchase or likelihood of purchase or willingness to purchase. Such a tendency or likelihood or willingness is influenced by a number of factors namely the categories of cultural, social, personal, psychological and marketing factors (Assael, 2004; Schiffman \& Kanuk, 2010), which fits the objective of the present study. Assael (2004) posits that the elements of the marketing mix are critical to the purchase behaviour of consumers and these elements may include the advertising strategy or branding. Purchase intention or willingness to buy has been confirmed to be positively associated with some marketing factors, such as brand attitude and brand image (Shah et al., 2012; Rao \& Monroe, 1988) as well as some social factors, such as intergenerational influences (Heckler et al., 1989; Moore et al., 2002).

Brand awareness is recognised as an important determinant of purchase behaviour (Keller, 1993). It concerns 'the strength of consumers' memory in terms of brand node or trace' (Grant et al., 2008; p.277), which may represent the value that a brand name can bring to a product (Keller, 1993). It also concerns how well consumers can distinguish a brand from its competitors' (Rossiter \& Percy, 1987). Rossiter and Percy (1987) and Keller (1993) argue that establishing brand awareness is a necessary objective for marketers to achieve as some attitudes consumers may develop to a product or service may eventually influence their purchase behaviour. This might be attributed to the fact that brand awareness saves time and energy for consumers in researching for information. Thus, they tend to choose those brands that they are aware of. Therefore, Konecnik and Gartner (2007) argue that the selection of a given brand first requires brand awareness in order to facilitate the purchase. It has been agreed that brand awareness is an important factor in examining whether a brand is successful or not (Grant et al., 2008). A product with a higher level of brand awareness has been confirmed to be associated with higher market shares and quality evaluation (Grewal, Monroe, \& Krishnan, 1998). Hoeffler and Keller (2002) point out that brand awareness can be distinguished by depth and width. The depth of brand awareness refers to how easy it is for consumers to recall or identify a brand while the width of brand awareness refers to how likely consumers are to think about a brand when purchasing a product (Hoeffler \& Keller 2002). It is concluded that brand awareness has a causal effect on purchase behaviour (Keller, 1993). Thus Leong (1993) and Macdonald and Sharp (2000) refer brand awareness as a heuristic when consumers purchase or select a product.

According to Morgan and Hunt (1994), purchase behaviour is a relational asset of market implications for the development and maintenance of trust. Hiscock (2001) argues that the ultimate goal of marketing is to generate an intense bond between the consumer and the brand. One of the most critical tasks in the bond is to build brand trust (Delgado, Frank, \& Phelps, 2005; Hiscock, 2001). Deutsch (1958) defines trust as a person's willingness to be dependent on another party in the belief that the party will not intentionally disappoint them, while Gulati (1995) defines trust as a type of expectation that alleviates the fear that one's partner will act opportunistically. Alternatively, trust is placed in people (Mayer, Davis, \& Schoorman, 1995) and can be described as a 'psychological state comprising the intention to accept vulnerability based on positive expectations of the intentions or behaviour of another' (Rousseau, Sitkin, Burt, \& Camerer, 1998, p. 396). In the marketing literature, brand trust can be defined as 'a consumer's willingness to rely on the brand in the face of risk because of expectations 


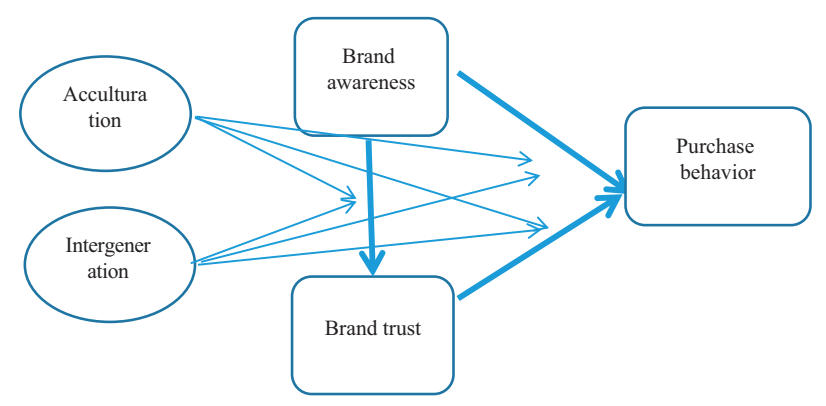

Figure 2. The Proposed Framework.

that the brand will cause positive outcomes' (Lau \& Lee, 1999, p. 344). Some scholars such as Dahlgren (2011) believe brand trust is a key driver of purchase behaviour due to the exchange relationship it facilitates. In this respect, it is important to focus on building and maintaining brand trust since it represents the basis to develop a long-term customer relationship (Burmann, Schaefer, and Maloney, 2009). Researchers have found out that brand trust can reduce uncertainty dramatically when consumers are choosing brands, and as a result, their purchase intention is determined by consumers' brand trust (Chaudhuri \& Holbrook, 2001; Lau \& Lee, 1999). Brand trust is also considered as a bond between a consumer and a firm (Fournier, 1998) as the performance of a firm is dependent on the bond, which is about how likely customers would be to make a purchase.

As in the existing literature, purchase behaviour is affected by brand awareness and mediated by brand trust. This relationship can be depicted as follows in Figure 1.

Today's societies, however, cannot escape the impact of social factors that have been promoted by globalisation, in which consumers are exposed to global brands. At the centre of the complex is the readiness of consumers for such global brands and foreign cultures (Durvasula \& Lysonski, 2015) among other classic social factors such as reference group (Bearden \& Etzel, 1982), power state (Rucker \& Galinsky, 2008), etc. Acculturation and intergenerational influences have been brought into the present study. Acculturation is defined as the process of change that results from continuous first-hand contacts between people from different cultures (Redfield, Linton, \& Herskovits, 1936). There is a debate in the field regarding whether the unidimensional model or the bi-dimensional model should hold (Kang, 2006). This paper followed the bi-dimensional model, which considers the minority culture that is independent of the mainstream culture as: 'the bi-dimensional model is able to embrace not only individuals with bicultural identities but also people who are not attached to either culture' (Kang, 2006; p.670). Therefore, not only might people from the minority culture move towards the mainstream culture but the other directional movement is also possible. The advantage of using acculturation is that if consumers are becoming more convergent, as argued by Durvasula and Lysonski (2015), then it is easier for businesses to adopt transnational marketing strategies that would be acculturated to global consumer culture. The question is how to treat acculturation in brand research. Acculturation is about consumer exposure to the marketing activities of multinationals, language usage and exposure, social interactions, global mass media exposure, openness and desire to emulate global consumer culture, and self-identification with global consumer culture (Cleveland \& Laroche, 2007). Therefore, the role acculturation plays might not be as direct as those marketing factors on purchase behaviour but it does moderate the relationships of marketing factors and purchase behaviour.

In consumer research, it has been stressed that parents do influence their children on their purchase behaviour through passing on information, attitudes, beliefs, resources and behaviour (Heckler et al., 1989; Moore et al., 2002) and vice versa (De Mol \& Buysse, 2008). This is identified as intergenerational influence. The general knowledge, on the one hand, is about children's consumer behaviour emerging in their early ages due to such an influence (McAlister \& Cornwell, 2010). For example, it has been evidenced that the brands that are used in childhood are still being used in adulthood. The intergenerational influence is found to be in the two areas: cognitive and environmental (Haynes et al., 1993). Hsieh, Chiu, and Lin (2006) argue that communicative effectiveness is key to the positive transfer of intergenerational influence. There is some extant literature on the positive effect of intergenerational influence on brand awareness, associations, attitudes and the perceived quality of brands (Bravo Gil et al. 2007; Hsieh et al., 2006). On the other hand, children do influence their parents, something which has been recognised since as early as 1960s (Bell 1969). Unlike the former approach, this approach studies children's effects on parents in a non-agentic way (Russell \& Russell, 1992). It indicates that, although it has been 
Table 1. CFA of the model and model fitness.

\begin{tabular}{|c|c|c|c|c|c|}
\hline & AW & W & ACC & $\mathrm{T}$ & IN \\
\hline AW2 & 0.836 & & & & \\
\hline AW3 & 0.847 & & & & \\
\hline AW4 & 0.798 & & & & \\
\hline AW5 & 0.793 & & & & \\
\hline W2 & & 0.804 & & & \\
\hline W3 & & 0.808 & & & \\
\hline $\mathrm{ACC} 1$ & & & 0.838 & & \\
\hline ACC2 & & & 0.835 & & \\
\hline ACC3 & & & 0.763 & & \\
\hline ACC4 & & & 0.813 & & \\
\hline $\mathrm{T} 1$ & & & & 0.694 & \\
\hline $\mathrm{T} 2$ & & & & 0.813 & \\
\hline T3 & & & & 0.821 & \\
\hline T4 & & & & 0.805 & \\
\hline IN1 & & & & & 0.834 \\
\hline IN2 & & & & & 0.887 \\
\hline IN3 & & & & & 0.844 \\
\hline \multicolumn{6}{|c|}{ Correlation } \\
\hline \multicolumn{6}{|c|}{ AW } \\
\hline W & 0.35 & & & & \\
\hline ACC & 0.02 & 0.11 & & & \\
\hline $\mathrm{T}$ & 0.12 & 0.21 & 0.16 & & \\
\hline IN & 0.11 & 0.17 & 0.15 & 0.11 & \\
\hline GFI & & & 0.978 & & \\
\hline CFI & & & 0.990 & & \\
\hline RMSEA & & & 0.03 & & \\
\hline
\end{tabular}

recognised that children do influence their parents, it concerns effects that 'do not entail much active involvement on the part of the child (e.g. the child's age, gender, temperament)' (De Mol \& Buysse, 2008; p.164).

It is believed that due to social factors such as acculturation and intergenerational influence, the formation of consumers' brand awareness and brand trust might be changed and thus would affect how marketing factors affect purchase behaviour. It is not entirely clear at this stage how strong the moderation effects of these social factors (acculturation and intergenerational influence) would be, which is exactly what the researchers attempted to find out. The proposed framework of the present paper is depicted in Figure 2.

\section{Methodology}

\section{Measurement}

Given the proposed framework as featured in Figure 2, a questionnaire was designed to capture the five constructs. Acculturation was measured as in Durvasula and Lysonski (2015); intergeneration was measured as in Cai et al. (2015); brand awareness was measured by using the methods in Aaker (1996); brand trust was measured according to the approach of Lau and Lee (1999) and, lastly, willingness to learn to measure purchase behaviour, which was taken as purchase behaviour in the study, was measured as in Miller et al. (2011).

\section{Data collection}

There are thirteen Chinese schools in Ireland providing Chinese lessons as of May 2017, of which seven are affiliated to some social or professional associations and six are privately owned. Most of the schools provide Chinese lessons, not only to local children born to Chinese parents or one Chinese parent, but also to Irish students. Given the recent announcement that Chinese will be a Leaving Certificate subject, it is predicted that there will be more people showing an interest in learning Chinese in Ireland. The thirteen Chinese schools employ 101 teachers, of whom 23 trained to be teachers in China and 71 obtained their first degrees from China.

The questionnaire was administered in a few Dublin and Cork schools among those transition year students and their parents who took Chinese lessons. Before the questionnaire was administered, a one-hour session of training was provided to the Chinese teachers, who actually administered the questionnaire in class. A $t$-test was performed to compare the different data coming from different schools and regions in Ireland before they were 


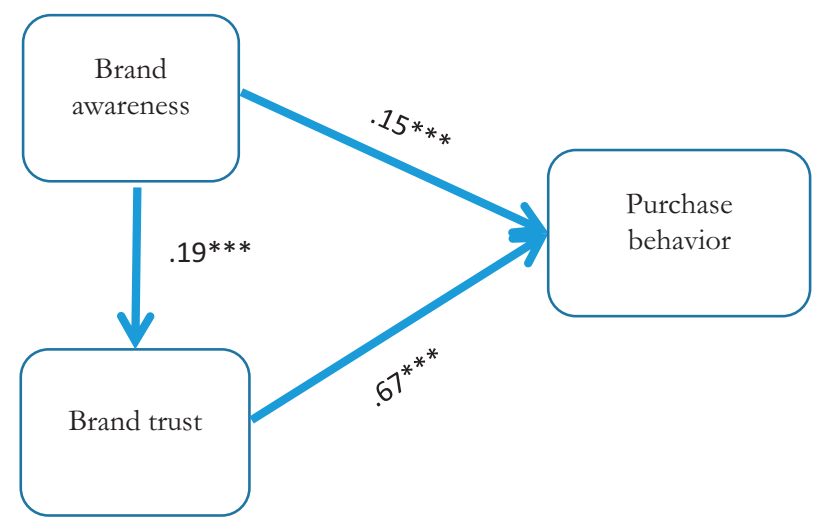

Figure 3. Path Analysis of Model I (with marketing factors only).

combined into one dataset. No significant difference was identified. The total number of questionnaires completed by students that were collected was 1473 . Data were first screened by treating missing data and cleaning data to ensure the multivariant normality. Along with other tests, the Mahalanobis was computed accordingly. By using a degree of freedom table, there were a few cases that showed multivariate abnormality and these were deleted from the data set. The final number of usable observations in the dataset was 1393, which made a usable rate of $94.5 \%$.

\section{Data analysis}

Data were first analysed by using exploratory factor analysis (EFA). After the measurement was confirmed to be valid for each construct, a confirmatory factor analysis (CFA) was performed. The results are presented in Table 1.

The model fit indexes are GFI being 0.978 , CFI being 0.990, and RMSEA being 0.03, all within the satisfactory levels. Once the CFA was done, the study proceeded to the next stage, which was to test whether having the two social factors, i.e. the two moderators would change the relationships between marketing factors, namely brand awareness, brand trust and a willingness to learn Chinese with a certain Chinese language school (purchase behaviour). To reach the objective, there were three stages of analysis. In Stage One, a model, Model I was built with only the marketing factors to find out the $\beta$ coefficients of brand awareness and brand trust on purchase behaviour. This was done in SEM. In Stage Two, a different model, Model II was built, which included the two moderators, acculturation and intergenerational influence. This was done by using Andrew Hayes' macro Model 76 in SPSS. In Stage Three, the $\beta$ coefficients of Model I and Model II were compared to examine the effect of the social factors on marketing factors. Figure 3 presents the results of Stage One, while Table 2 depicts the results of Stage Two and Figure 4 shows the results of Stage Three.

The model fit indexes are: RFI being 0.980, CFI being 0.992, and RMSEA being 0.04, all of which are satisfactory. In the model, Brand awareness has a significant positive effect on Brand trust (the $\beta$ coefficient being $0.19^{* * *}$ ) and on Purchase behaviour (the $\beta$ coefficient being $0.15^{* * *}$ ) and brand trust is positively associated with purchase behaviour (the $\beta$ coefficient being $0.67^{* * *}$ ). The findings seem to support the extant literature (Chaudhuri \& Holbrook, 2001; Grant et al. (2008; Keller, 1983; Morgan \& Hunt, 1994).

In Model II, the two concerned social factors, intergenerational influence and acculturation were taken on board and treated as moderators (see Figure 4). Given the complexity of the model, Andrew Hayes's Macro in SPSS was used for data analysis purposes. Results are presented in Table 2.

In order to compare Model I and Model II, Figure 4 was created.

As illustrated in Figure 4 it is obvious that when the two social factors were not included in the model as in Model I, the $\beta$ coefficients of brand awareness on brand trust was $0.19^{* * *}$, and when the two moderators were included in the model, the $\beta$ coefficient was increased to $0.39^{*}$, though at a lower significance level. The findings support Rossiter \& Percy (1987) and Keller (1993) that to establishing brand awareness is necessary as some attitudes consumers may develop to a product or service may eventually influence their purchase behaviour. It confirmed that brand awareness is more about their attitude (Macdonald \& Sharp, 2000), it may be retained in a long term with consumers (Laroche, Kim \& Zhou, 1996). In the present research, it is clear that when the two social factors were excluded, the students' brand awareness had a significant effect on brand trust that these 
Table 2. Model II Results by Andrew Hayes' Macro in SPSS.

\begin{tabular}{|c|c|c|c|c|c|c|}
\hline & $\beta$ & SE & $t$ & $p$ value & $\mathrm{LLCl}$ & ULCI \\
\hline Constant & -0.7811 & 0.7760 & -1.0066 & .3143 & -2.3033 & 0.7411 \\
\hline Brand Trust & 0.0410 & 0.2261 & 0.1815 & .8560 & -0.4025 & 0.4845 \\
\hline Brand Awareness & 1.0400 & 0.2019 & 5.1518 & .0000 & 0.6440 & 1.4360 \\
\hline Acculturation & 0.3659 & 0.1987 & 1.8416 & .0657 & -0.0239 & 0.7557 \\
\hline Intergenerational influence & -0.0014 & 0.1133 & -0.0124 & .9901 & -0.2237 & 0.2209 \\
\hline Trust $\times$ Awareness & 0.0103 & 0.0555 & 0.1854 & .8529 & -0.0986 & 0.1192 \\
\hline Trust $\times$ Intergeneration & 0.0306 & 0.0287 & 1.0650 & .2871 & -0.0258 & 0.0870 \\
\hline Awareness $\times$ Acculturation & -0.1184 & 0.0496 & -2.3875 & .0171 & -0.2156 & -0.0211 \\
\hline Awareness $\times$ Intergeneration & -0.0107 & 0.0295 & -0.3636 & .7162 & -0.0685 & 0.0471 \\
\hline
\end{tabular}

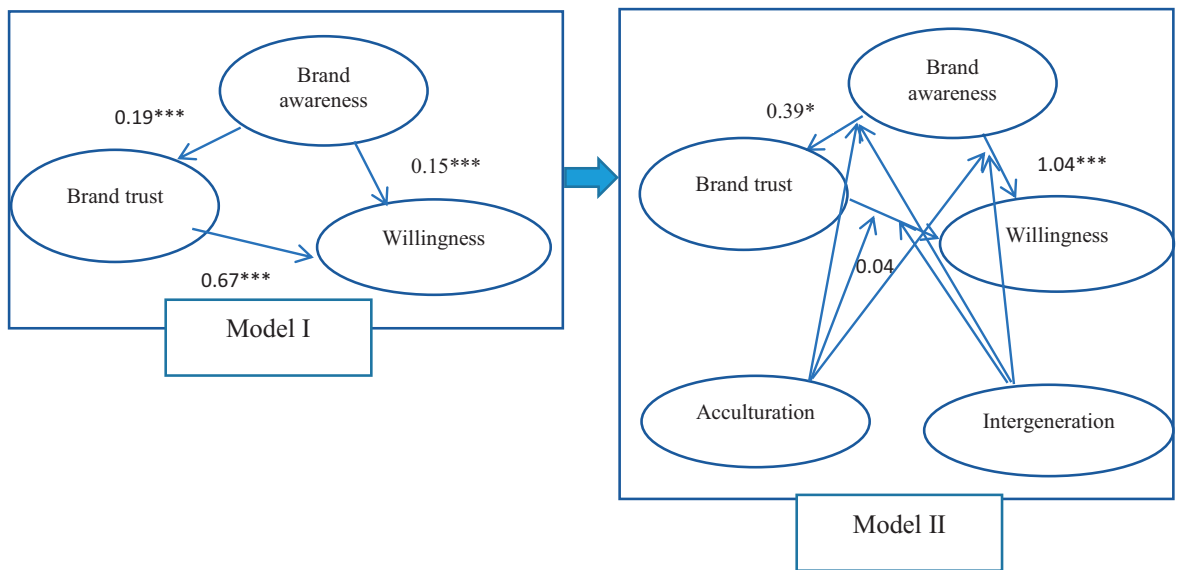

Figure 4. Comparison of Model I and Model II. $p$-value: ${ }^{* *} p<.001,{ }^{* *} p<.01,{ }^{*} p<.05$.

students had over the brand of the language school that they are willing to choose. However, when their parents' influence and their acculturation levels were taken into consideration, the importance of their brand awareness on brand trust was intensified, the $\beta$ was increased from 0.19 to 0.39 , albeit the statistical power was reduced. To the Irish transition year students, their parents may not have as much influence on their attitudes towards what language they would like to learn and where they learn it. Their acculturation levels did not moderate the effect of their brand awareness of a language school to learn Chinese on their selection.

Secondly, the $\beta$ coefficient of brand awareness and consumers' willingness to learn Chinese was $0.55^{* * *}$ without the social factors in Model I but the $\beta$ coefficient was fortified to $1.04^{* * *}$ when parents influence and their acculturation levels were introduced in Model II. Grewal et al. (1998) argue that higher levels of brand awareness have been confirmed to be associated with higher market shares and quality evaluation. In choosing cultural products like the present one, students relied on their assessment of the influential power of the language and the school. It could be inferred that to the Irish transition year students as well as their parents if students are under the influence of acculturation and intergenerational relationship, brand awareness is a more important attributing factor in their willingness to choose a Chinese language school. The finding reinforced the argument of Rossiter \& Percy (1987) on the fact that brand awareness comes from consumers' evaluation of the quality of a product or service. The implication here is that in Ireland the Chinese language schools need to spend more resources in building brand awareness among Irish consumers. In accordance with Macdonald and Sharp (2003), it is found that brand awareness can contribute to consumers forming the evoked set for purchase consideration as well their final decision on their purchase.

Thirdly, the $\beta$ coefficient between brand trust and the willingness to learn Chinese was $0.67^{* * *}$ without the social factors in Model I, yet the $\beta$ coefficient was reduced significantly to 0.04 when the two social factors were taken on board in Model II. This simply indicates that when the two social factors were excluded, brand trust of students on the Chinese language schools was significantly positive in relation to their choice of a school to learn Chinese. According to Deutsch (1958), trust is defined as a person's willingness to be dependent on another party in the belief that the party will not intentionally disappoint them. Such an effect disappeared when the two social factors were included in Model II. The intergenerational influence examines the personal interaction between parents and children. The information parents and children have, and their beliefs and attitudes would perhaps overcast the belief of consumers of their own (Moore et al., 2002). Therefore, it was implied in the present 
research that if the Chinese language schools would like to attract more students to learn Chinese, they must understand that the parents of students do influence their decision and it is likely that brand trust will lose its impact on the willingness of students to choose a particular school to learn Chinese. The definition of trust in Rousseau et al. (1998) placed importance on the influence of other people. It is not surprising that the transition year students in the present study are under influence of their parents.

\section{Conclusion}

In conclusion, the significance of the study is on when consumer research is carried out, both social factors and marketing factors should be included. As shown in the above discussion, the two social factors, namely acculturation and intergenerational influences, changed the relationships dramatically between brand awareness, brand trust and consumers' willingness to learn Chinese. Apparently, without looking at social factors, suggestion could be made to practitioners that brand awareness and brand trust need to be improved in order to foster consumers' willingness, as Model I might suggested. However, with some social factors being included as moderators, namely acculturation and intergenerational influence in the present study, brand awareness has a significant impact on brand trust and students' willingness to learn Chinese in a particular school. At the same time, the two social factors when included in brand research diminished the impact of brand trust on consumers' willingness. This finding is something that traditional studies would not be able to demonstrate. In today's society, when it comes to choosing a brand, an individual consumer is not only influenced by those marketing factors, but also social factors such as parental influence and levels of the acculturation of the young consumers.

The present research is among the first pilot studies to argue that both social and marketing factors need to be included in consumer research to help differentiate the effects of these factors. It should be noted that the moderation impact of the two social factors, i.e. intergenerational influence and acculturation are confirmed in the present study. Rao and Monroe (1988) argued that previous information could moderate the effect of some marketing factors on brand equity. In the present paper, parents influence and acculturation are arguably to be a type of previous information, not possessed by consumers themselves but their parents and their previous learning.

The limitation of the research can be to do with the research subject, which is cultural: to choose a language school to learn a language, Chinese. Owing to the fact that Chinese was announced to be a leaving cert subject in Ireland and China was also on the recent top discussion forum in the Irish media - the Ireland-China relationship, both political and economic, has grown from strength to strength, there might be some students in the sample who are by nature Chinese language and culture lovers despite their parents and social influences. Hence the impact of brand awareness is so strong and the effect of brand trust could be lost once their parents' influence and their acculturation levels were considered. Similarly, there might be some students who became to place Chinese on their learning agenda under the influence of their parents and society due to the consideration of their career prospect in the context of the uncertainties that might be created by Brexit. Hence the intergenerational influence and acculturation could reduce the effect of brand trust on consumers' willingness in the present study.

\section{Disclosure statement}

The authors declare the originality of the paper. The terms of this arrangement have been reviewed and approved by the Central South University, China in accordance with its policy on objectivity and ethics in research.

\section{ORCID}

Xiaohong Li iD http://orcid.org/0000-0001-5989-6540

\section{References}

Aaker, D.A. (1996). Building Strong Brands. New York: The Free Press. 
Ajzen, I. (1991). The theory of planned behavior. Organizational Behavior and Human Decision Processes, 50, 179-211. doi: 10.1016/0749-5978(91)90020-T

Assael, H. (2004). Consumer Behavior: A Strategic Approach, New York: Houghton Mifflin Company. doi:10.1086/ahr/20.2.396

Bearden, W.O., \& Etzel, M.J. (1982). Reference group influence on product and brand purchase decisions. Journal of Consumer Research, 9, 183-194.

Bravo Gil, R. , Fraj-Andres, E. and Salinas, E. M. (2007). Family as a Source of Consumer-Based Brand Equity. Journal of Product \& Brand Management, 16: 188-199. doi:10.1108/10610420710751564

Burmann, C., Zeplin, S. and Riley, N. (2009). Key Determinants of Internal Brand Management Success: An Exploratory Empirical Analysis. Journal of Brand Management, 16: 264-284. doi:10.1057/bm/2008.6

Cai, Y., Zhao, G., \& He, J. (2015). Influences of two modes of intergenerational communication on brand equity. Journal of Business Research, 68, 553-560. doi:10.1016/j.jbusres.2014.09.007

Chaudhuri, A., \& Holbrook, M.B. (2001). The chain effects from brand trust and brand affect to brand performance: the role of brand loyalty. Journal of Marketing, 65, 81-93. doi:10.1509/jmkg.65.2.81.18255

Chowdhury, M.H.K. (2007). An investigation of consumer evaluations of brand extensions. International Journal of Consumer Studies, 31, 377-384. doi:10.1111/j.1470-6431.2006.00568.x

Cleveland, M., \& Laroche, M. (2007). Acculturation to the global consumer culture: Scale development and research paradigm. Journal of Business Research, 60, 249-259. doi:10.1016/j.jbusres.2006.11.006

Dahlgren, S. (2011). Brand loyalty and involvement in different customer levels of a service concept brand, Aalto University, School of Economics. Working Paper.

De Mol, J., \& Buysse, A. (2008). The phenomenology of children's influence on parents. Journal of Family Therapy, 30, 163-193. doi:10.1111/j.1467-6427.2008.00424.x

Delgado, M.R., Frank, R.H., \& Phelps, E.A. (2005). Perceptions of moral character modulate the neural systems of reward during the trust game. Nature Neuroscience, 8, 1611-1618. doi:10.1038/nn1575

Deutsch, M. (1958). Trust and suspicion. Journal of Conflict Resolution, 2, 265-267. doi:10.1177/002200275800200401

Durvasula, S., \& Lysonski, S. (2015). Cross-national applicability of a parsimonious measure of acculturation to global consumer culture. Psychological Reports, 116, 738-750. doi:10.2466/01.08.PR0.116k29w6

Fournier, S. (1998). Consumers and their brands: developing relationship theory in consumer research. Journal of Consumer Research, 24, 343-353. doi:10.1086/209515

Grant, P., Botha, E., \& Kietzmann, J. (2008). Branded flash mobs: moving toward a deeper understanding of consumers' responses to video advertising. Journal of Interactive Advertising, 1-15.

Grewal, D., Monroe, K.B., \& Krishnan, R. (1998). The effects of price-comparison advertising on buyers' perceptions of acquisition value, transaction value and behavioral intentions. Journal of Marketing, 62, 46-59. doi:10.2307/1252160

Gulati, R. (1995). Does familiarity breed trust? The implications of repeated ties for contractual choice in alliances. Academy of Management Journal, 38, 85-112. doi:10.2307/256729

Haynes, J., Burts, D., Dukes, A., \& Cloud, R. (1993). Consumer socialization of pre-schoolers and kindergartners as related to clothing consumption. Psychology and Marketing, 10, 151-166. doi:10.1002/mar.4220100207

Heckler, S.E., Childers, T.L., \& Arunachalam, R. (1989). Intergenerational influences in adult buying behaviors: An examination of moderating factors. Advances in Consumer Research, 16, 276-284.

Hiscock, J. (2001). Most trusted brands. Marketing, 1, 32-33.

Hoeffler, S. and Keller, K.L. (2002). Building Brand Equity Through Societal Marketing. Journal of Public Policy and Marketing, 21, 78-89.

Hsieh, Y.C., Chiu, H.C., \& Lin, C.C. (2006). Family communication and parental influence on children's brand attitudes. Journal of Business Research, 59, 1079-1086. doi:10.1016/j.jbusres.2006.09.016

Kang, S.M. (2006). Measurement of acculturation, scale, formats, and language competence: Their implications for adjustment. Journal of Cross-Cultural Psychology, 37, 669-693. doi:10.1177/0022022106292077

Keller, J. (1983). Motivational Design of Instruction. In C. M. Reigeluth (ed.) Instructional Design Theories and Models, Hillsdale: NJ.

Keller, K.L. (1993). Conceptualizing, measuring, and managing customer-based brand equity. Journal of Marketing, 57, 1-22. doi:10.1177/002224299305700101

Konecnik, M., \& Gartner, W.C. (2007). Customer-based brand equity for a destination. Annals of Tourism Research, 34, $400-421$. doi:10.1016/j.annals.2006.10.005

Laroche, M., Kim, C., \& Zhou, L. (1996). Brand familiarity and confidence as determinants of purchase intention: An empirical test in a multiple brand context. Journal of Business Research, 37, 115-120. doi:10.1016/0148-2963(96)00056-2

Lau, G.T., \& Lee, S.H. (1999). Consumers trust in brand and the link to brand loyalty. Journal of Market-Focused Management, 4 , 341-370. doi:10.1023/A:1009886520142

Leong, S.M. (1993). Consumer decision making for common, repeat-purchase products: A dual replication. Journal of Consumer Psychology, 2, 193-208. doi:10.1016/S1057-7408(08)80024-1

Macdonald, E., \& Sharp, B. (2000). Brand awareness effects on consumer decision making for a common, repeat purchase product: A replication. Journal of Business Research, 48, 5-15. doi:10.1016/S0148-2963(98)00070-8

Macdonald, E., \& Sharp, B. (2003). Management perceptions of the importance of brand awareness as an indication of advertising effectiveness. Marketing Bulletin, 14, Article 2. 
Mayer, R.C., Davis, J.H., \& Schoorman, D.F. (1995). An integrative model of organizational trust. Academy of Management Review, 20, 709-734. doi:10.2307/258792

McAlister, A., \& Cornwell, B.T. (2010). Children's brand symbolism understanding: Links to theory of mind and executive functioning. Psychology and Marketing, 27, 203-228. doi:10.1002/mar.20328

Miller, K.M; Hofstetter, R. and Krohmer H. (2011). How Should Consumers Willingness to Pay be Measured? An Emprical Comparison of State-of-the-Art Approaches. Journal of Marketing Resaerch, 48: 172-184.

Moore, E.S., Wilkie, W.L., \& Lutz, R.J. (2002). Passing the torch: Intergenerational influences as a source of brand equity. Journal of Marketing, 66, 17-37. doi:10.1509/jmkg.66.2.17.18480

Morgan, R.M., \& Hunt, S.D. (1994). The commitment-trust theory of relationship marketing. Journal of Marketing, 58, 20-38. doi: $10.1177 / 002224299405800302$

Rao, A., \& Monroe, K. (1988). The moderating effect of prior knowledge on cue utilization in product evaluations. Journal of Consumer Research, 15, 253-264. doi:10.1086/209162

Redfield, R., Linton, R., \& Herskovits, M.T. (1936). Memorandum for the study of acculturation. American Anthropologist, 38, 149-152. doi:10.1525/aa.1936.38.1.02a00330

Rossiter, J.R., \& Percy, L. (1987). Advertising and Promotion Management. Singapore: McGraw-Hill.

Rousseau, D.M.S., Sitkin, S.B., Burt, R.S., \& Camerer, C. (1998). Not so different after all: A cross-discipline view of trust. Academy of Management Review, 23, 393-404. doi:10.5465/amr.1998.926617

Rucker, D.D., \& Galinsky, A.D. (2008). Desire to acquire: Powerlessness and compensatory consumption. Journal of Consumer Research, 35, 257-267. doi:10.1086/588569

Russell, A. and Russell, G. (1992). Child Effects in Socialization Research: Some Conceptu-al and Data analysis Issues. Social Development, 1: 163-184.

Schiffman, L., \& Kanuk, L.L. (2010). Consumer Behavior (Global 10th ed). United State of America: Pearson Education.

Shah, S.S.H., Aziz, J., Jaffari, A. R., Waris, S., Ejaz, W., Fatima, M., \& Kamran Sherazi, S. (2012). The impact of brands on consumer purchase intentions. Asian Journal of Business Management, 4, 105-110. 